NASA/TM-1998-207414

NASA

Technical Characteristics of a Novel

Helical-Groove Traveling-Wave Tube Structure

Thomas M. Wallett, Karl R. Vaden, and Jon Freeman

Lewis Research Center, Cleveland, Ohio

A. Haq Qureshi

Cleveland State University, Cleveland, Ohio

National Aeronautics and

Space Administration

Lewis Research Center 
Trade names or manufacturers' names are used in this report for identification only. This usage does not constitute an official endorsement, either expressed or implied, by the National Aeronautics and Space Administration.

Available from

NASA Center for Aerospace Information 7121 Standard Drive

Hanover, MD 21076

Price Code: A02
National Technical Information Service 5287 Port Royal Road Springfield, VA 22100 Price Code: A02 


\title{
Technical Characteristics of a Novel Helical-Groove Traveling-Wave Tube Structure
}

\author{
Thomas M. Wallett, Karl R. Vaden, and Jon Freeman \\ NASA Lewis Research Center, Cleveland, Ohio 44135
}

A. Haq Qureshi

Cleveland State University, Cleveland, Ohio 44115

\begin{abstract}
Experimental measurements of the dispersion characteristics of a C-band helix structure were carried out and compared to the dispersion characteristics found from a helix model using the three-dimensional electromagnetic computer code MAFIA. A conceptually novel design comprising a helical thread of the same pitch and inner diameter in a cylindrical waveguide also were calculated using the MAFIA code. The helical-groove structure exhibits a smaller bandwidth but at a much higher frequency range than the traditional helical structure for similar physical dimensions. It is physically more robust in construction. The interaction impedance also compares favorably with those of the conventional structure.
\end{abstract}

Index Terms-MAFIA, helix, interaction impedance, helical-groove.

\section{INTRODUCTION}

For applications in high frequency communications and radar, small-size microwave power modules (MPM) are being developed which provide power at various levels, bandwidths, and frequencies. They incorporate miniature traveling-wave tubes (TWT) consisting of helical structures with inherent mechanical limitations. Advanced electromagnetic computer codes make it possible to accurately model and explore the suitability of other novel structures for these and other applications.

The helix TWT has served well for low-power, widebandwidth amplification of microwave energy [1]. The coupled-cavity TWT is preferred for medium- to highfrequency applications, but it suffers from the disadvantage of limited bandwidth [2]. The tunnel ladder structure has exhibited a bandwidth comparable to the helix with the disadvantage of complicated machining and fabrication [3].

A class of structures which could be easily fabricated for an MPM, having good power and bandwidth capabilities, is the helically-wrapped circular waveguide [4]. One such novel design consists of a cylindrical waveguide with a helical groove of rectangular cross section on the inside. To make a comparison, this structure was given the same pitch, thickness, and inner diameter as the Northrop C-band helix structure in Fig. 1 and modeled using MAFIA [5].

T. M. Wallett, 216-433-3673, fax 216-433-8705, wallett@lerc.nasa.gov, http://www.lerc.nasa.gov

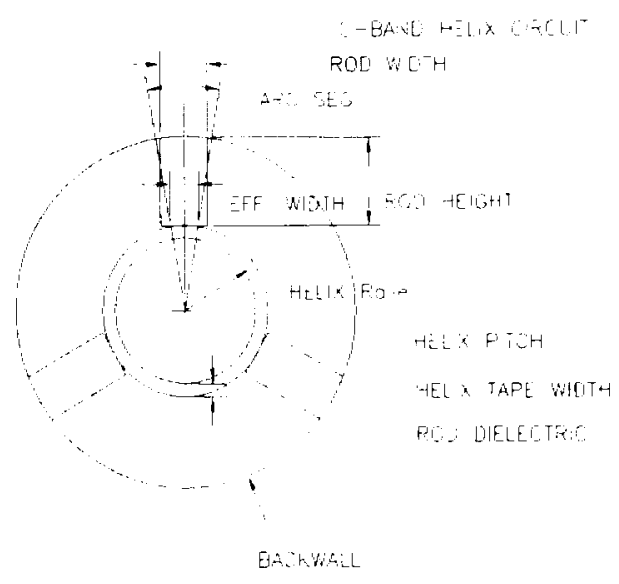

Fig. 1. Northrop C-Band Helix Structure. (Courtesy of Northrop)

\section{EXPERIMENTAL TESTING}

\section{A. Test Procedure}

Standard perturbation techniques on an HP $8510 \mathrm{C}$ network analyzer were used in the measurement of the Northrop C-band helix circuit to determine the dispersion characteristics and interaction impedances. These were compared with the values that Northrop had obtained by similar measurements [6].

A frequency range from 3.0 to $7.0 \mathrm{GHz}$ was chosen and measurements were taken at $0.5 \mathrm{GHz}$ increments. To obtain the dispersion characteristics, a thin, dielectric alumina rod with a metallic cap on the end was inserted from one side of the helix along the axis of the structure by means of a micrometer feed. As the rod is translated along the helix axis, a change in phase of the reflected wave parameter (S11 or S22 depending on which side the rod was inserted) occurs. Since each 360 degree phase shift corresponds to one-half the electrical wavelength, the wavelength for a specified frequency is twice the average distance the rod has moved for a 360 degree phase shift. The relative phase velocity is given as the ratio of the electrical wavelength to the free space wavelength.

The interaction impedance for a specified frequency is determined by measuring the phase shift that occurs when a thin, dielectric alumina rod of approximately the length of the structure is inserted along the helix axis. A Northrop FORTRAN program was then used to compute the helix interaction impedance from measured phase shifts resulting from perturbation by the dielectric rod. 


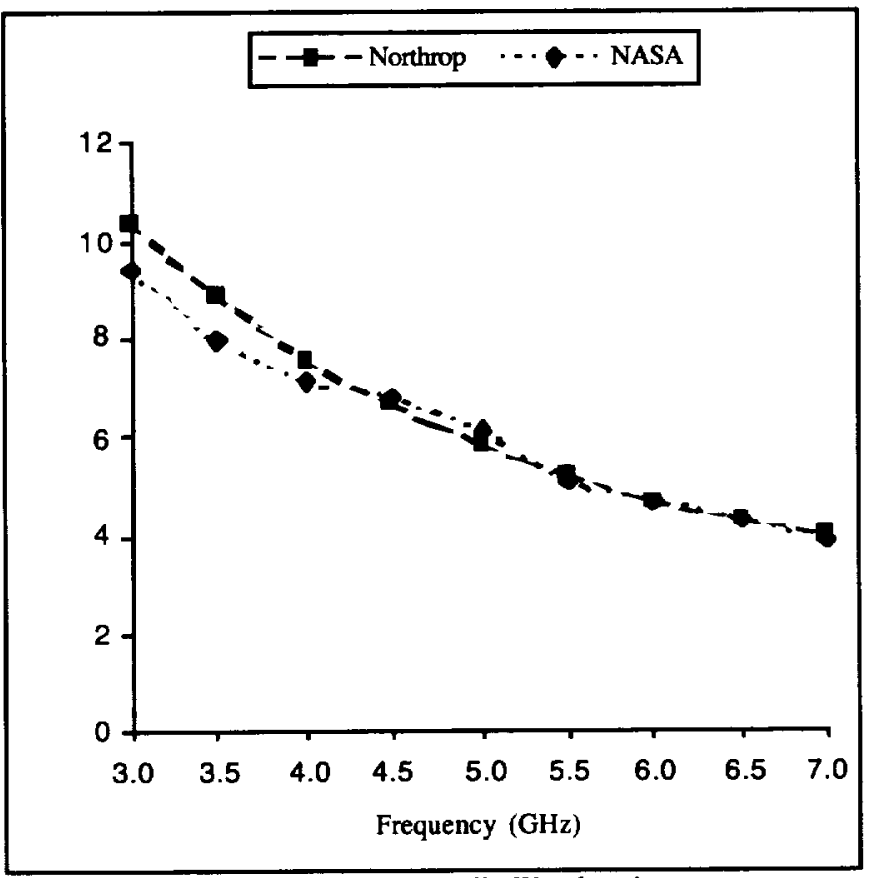

Fig. 2. Experimental Helix Wavelengths.

\section{B. Wavelength and Phase Shift Measurements}

The wavelengths and interaction impedances were calculated by Northrop from distance and phase shift measurements with an alumina dielectric $\left(\varepsilon_{\mathrm{r}}=9.3\right)$ rod of the helix length and diameter 0.0365 inch. These measurements were duplicated on an HP8510C network analyzer at NASA Lewis Research Center with an alumina dielectric $\left(\varepsilon_{r}=9.3\right)$ rod of the same length and diameter 0.031 inch. Comparisons are made between the Northrop and NASA wavelength measurements in Fig. 2 and the interaction impedances calculated using the Northrop program in Fig. 3.

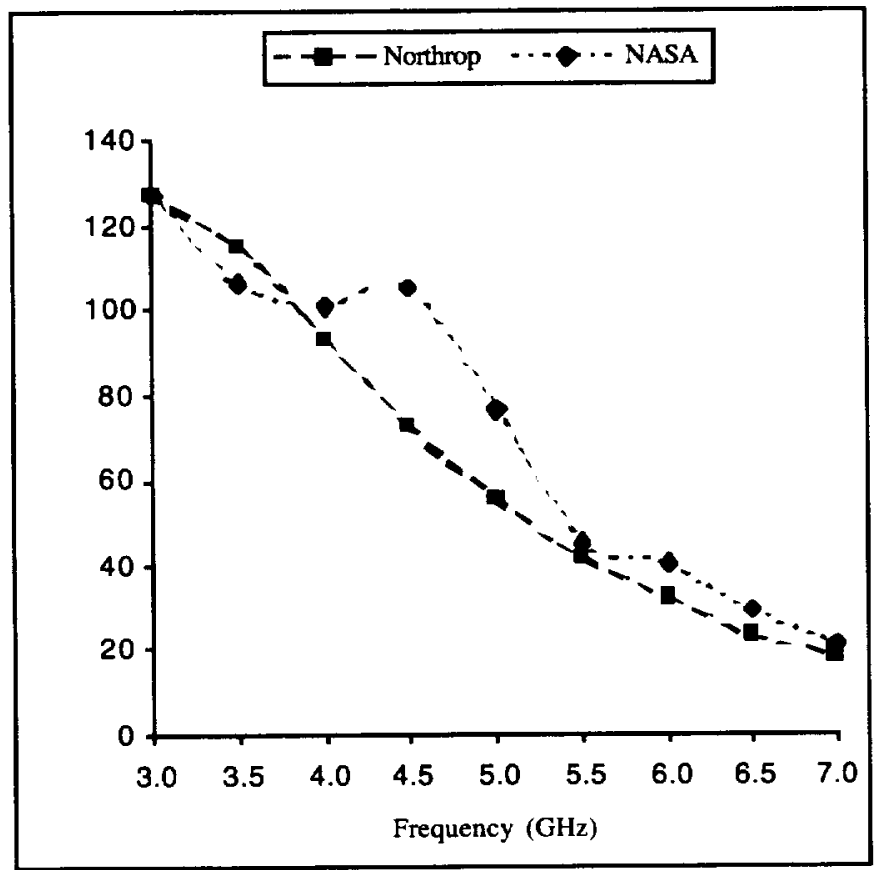

Fig. 3. Experimental Helix Interaction Impedances.
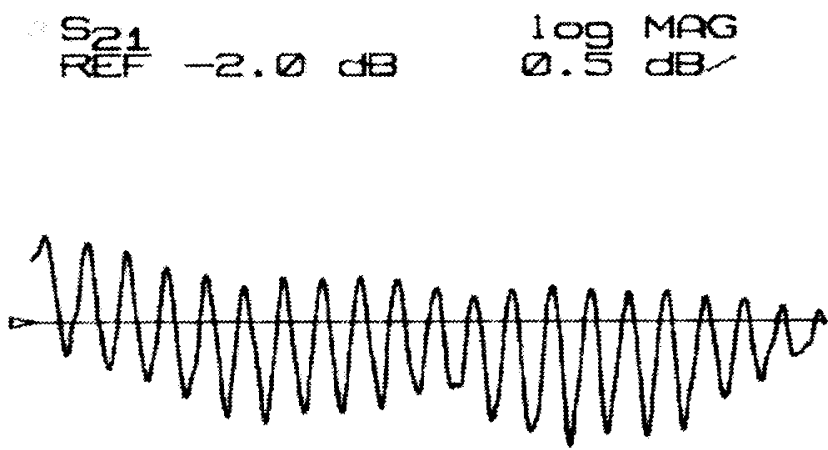

Fig. 4. S21 Parameters of the Northrop Helix Structure $(3-7 \mathrm{GHz})$.

\section{Wavelength and Frequency Shift Measurements}

Wavelength measurements were repeated for the frequency points corresponding to the local maxima and local minima of the logarithmic magnitude of the S21 transmission parameter in the range from 3.0 to $7.0 \mathrm{GHz}$ in Fig. 4. A least squares cubic fit of the frequency as a function of wavenumber was performed to deduce the resulting group velocities from the dispersion characteristics.

The frequency shifts of the local maxima and minima due to the perturbing effects of the 0.031 inch alumina dielectric rod were then measured. The interaction impedances were calculated using a basic formula depending on the group velocities, frequency shifts, and dielectric rod parameters.

\section{COMPUTER MODELING}

\section{A. MAFIA Helix Model}

One period of the actual Northrop C-band helix circuit was modeled using the computer code, MAFIA, as shown in Fig. 5. The coordinate system chosen was the $f z$ or cylindrical coordinate system. The three dielectric support rods were more easily modeled as small degree wedges with a slightly smaller effective width near the helix. This will result in a dielectric support rod cross-sectional area that is very nearly the same as that of the actual rod.

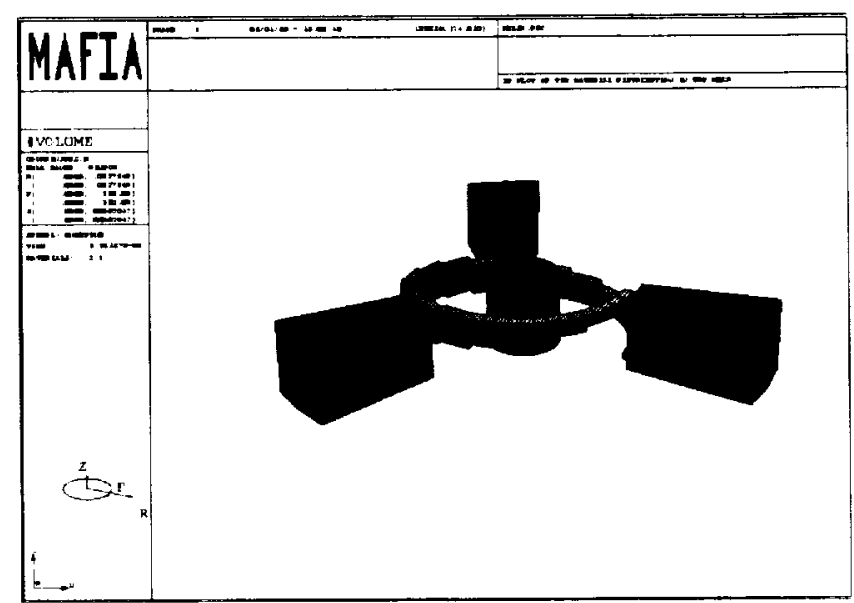

Fig. 5. MAFIA Helix Structure. 


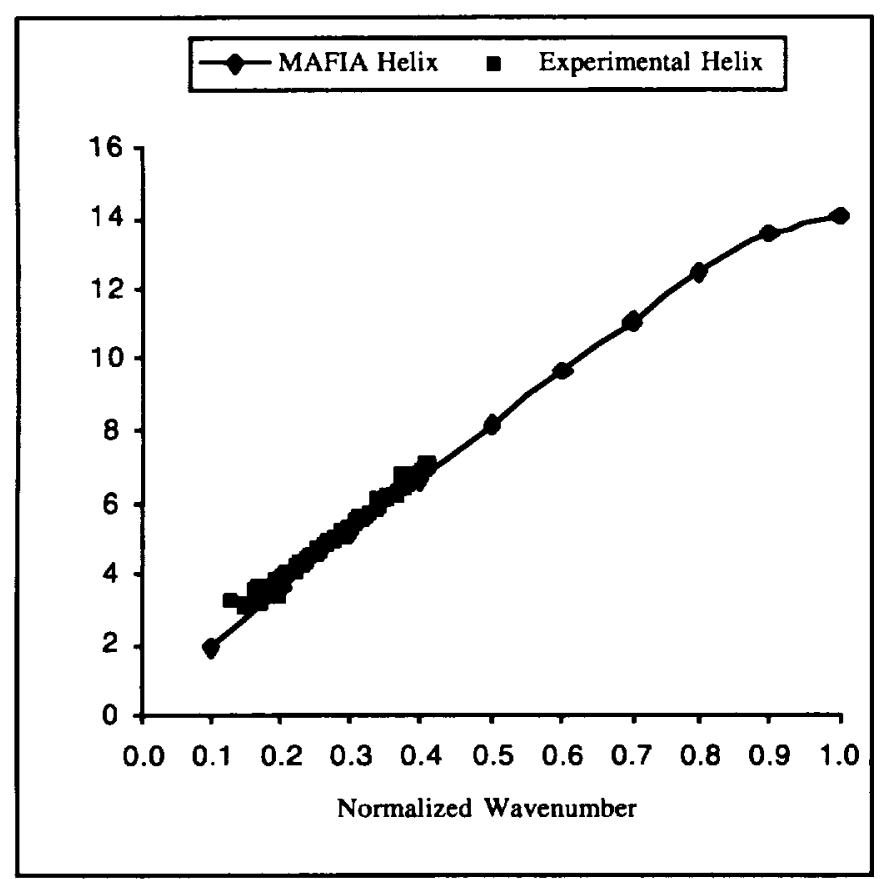

Fig. 6. Experimental and MAFIA Helix Dispersion Characteristics.

Periodic boundary conditions in the axial direction were applied to simulate an extended helix. The phase shifts per period were specified as multiples of 18 degrees and the corresponding frequencies were then calculated to find the dispersion characteristics. A least squares cubic fit to these data was also done. The simulated and experimental dispersion characteristics of the helix were then compared in Fig. 6 and found to agree.

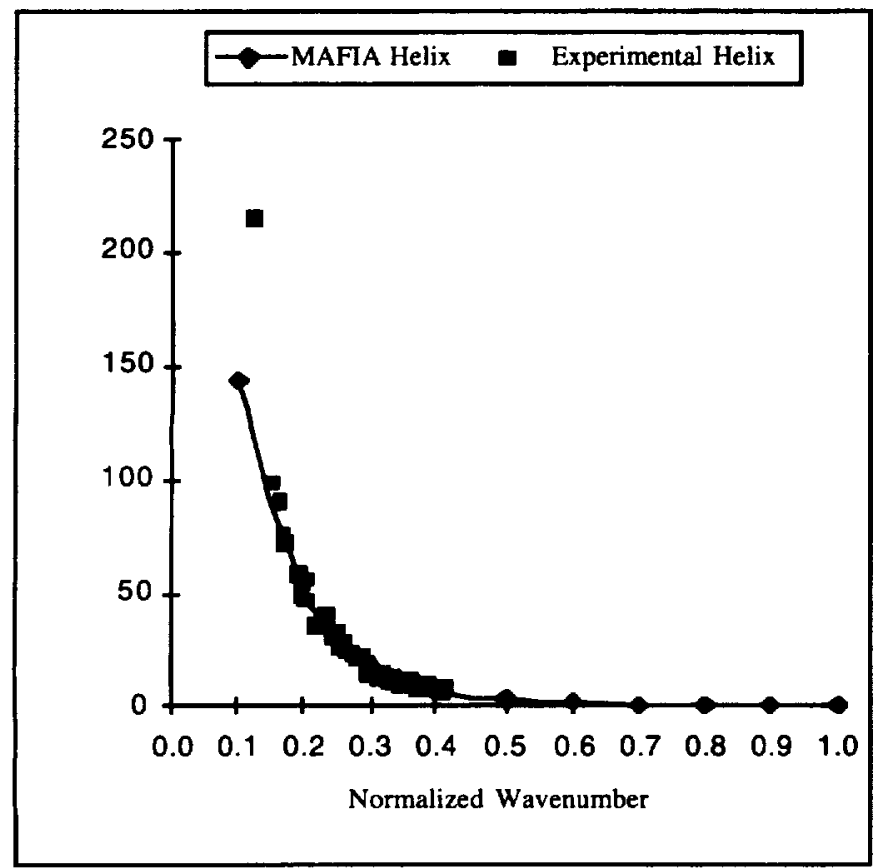

Fig. 7. Experimental and MAFIA Helix Interaction Impedances.
The MAFIA computer simulation was repeated under the same conditions except, this time, with a simulated dielectric $\left(\varepsilon_{\mathrm{r}}=9.3\right)$ rod along the length of the helical axis. The perturbed frequencies were calculated and the interaction impedances were found from the frequency shifts using the same basic formula so that a comparison could be made with the experimental results. The interaction impedances from the MAFIA simulation were in good agreement with those from the experimental measurements in Fig. 7 except at low wavenumbers where the measurements were inaccurate.

\section{B. MAFIA Helical-Groove Model}

The helical-groove structure was considered because it would possess, in part, the high-power capability of a coupled cavity structure along with the high-bandwidth capability of the helix. One period of the structure was modeled using MAFIA and shown in Fig. 8. The same dimensions as those in the helix structure were used; i.e., helix inner radius, pitch, and tape width. The groove and helix structures differ in that the thread contacts the cylinder wall whereas the helix was supported by three dielectric rods. Once again, the coordinate system chosen was the $r f z$ or cylindrical coordinate system.

Periodic boundary conditions were applied in the axial direction to simulate an extended groove. The phase shifts per period were specified as multiples of 18 degrees as in the case of the helix model and the corresponding frequencies were then calculated to find the dispersion characteristics. A least squares cubic fit to these data was made. The simulated dispersion characteristics of the groove structure were compared with the simulated dispersion characteristics of the helix structure in Fig. 9.

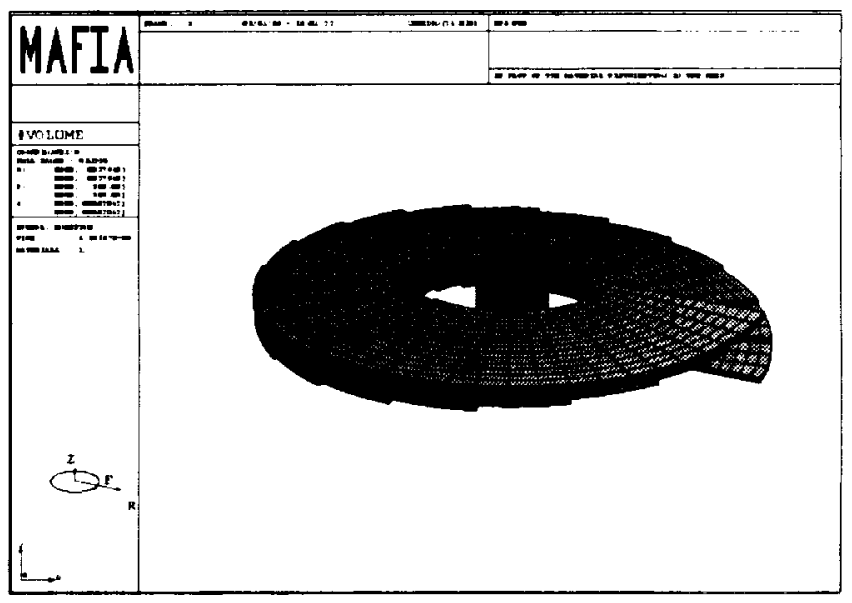

Fig. 8. MAFIA Helical-Groove Structure. 


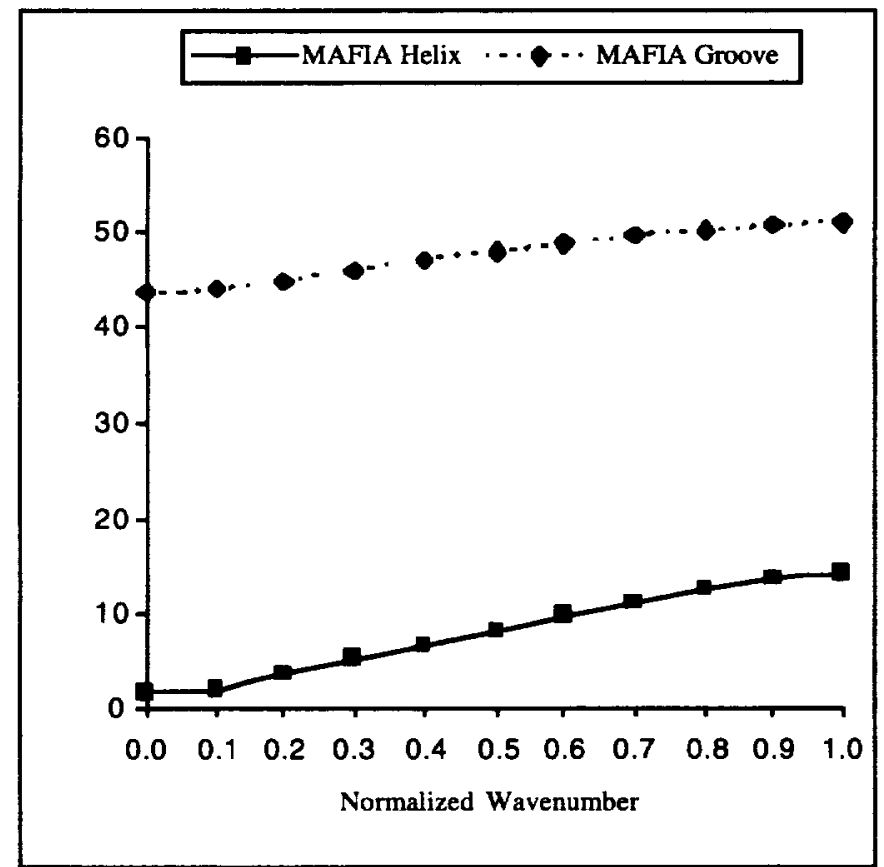

Fig. 9. MAFIA Helix and Helical-Groove Dispersion Characteristics.

The MAFIA helical-groove simulation was repeated under the same conditions except, this time, with a simulated dielectric $\left(\varepsilon_{r}=9.3\right)$ rod along the length of the helical axis. The perturbed frequencies were calculated and the interaction impedances were found from the frequency shifts by means of the same basic formula and a comparison was made with the simulated helix impedances. The interaction impedances from the MAFIA helical-groove simulation compared favorably with those from the helix simulation results as can be seen in Fig. 10.

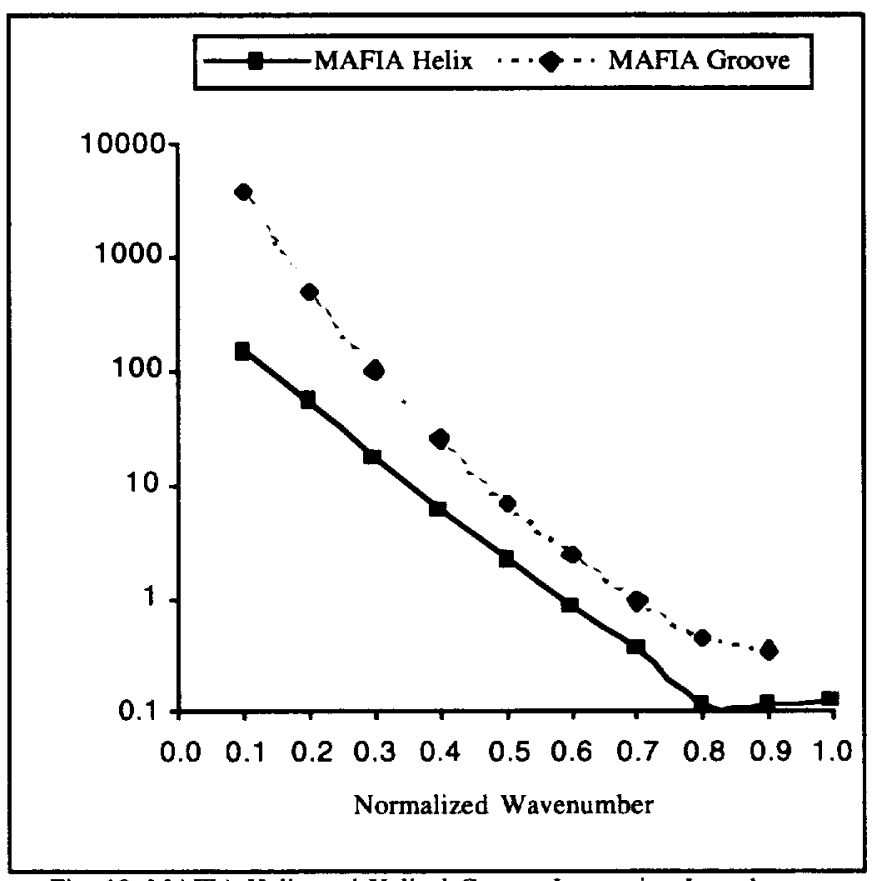

Fig. 10. MAFIA Helix and Helical-Groove Interaction Impedances.

\section{DISCUSSION}

The helical-groove structure can be fabricated more easily than a helix structure since it has no support rods, although dielectric loading could be used to shape the dispersion characteristics. It has a much more robust construction than the helix structure of similar dimensions and would survive events catastrophic for a helix device. Furthermore, the radial dimensions of the helical-groove can be made larger than those of the helix for high frequency operation.

The magnetic focusing required for such a device could be relaxed for operation within a certain frequency range in comparison to that for a helix device in which the electron beam cross-sectional area would have to be smaller for operation in the same frequency range.

The helical-groove structure would exhibit a higher bandwidth compared to coupled-cavity structures and a higher power capability compared to helix-type structures. Also for similar dimensions, the interaction impedance of the helical-groove is higher than the helix, especially at low wavenumbers, but since this structure has properties related to the coupled-cavity, the operation of an electronbeam device of this type would require much higher beam voltages.

\section{REFERENCES}

[1] T. M. Wallett and A. H. Qureshi, "Review of slow-wave structures," NASA Technical Memorandum 106639, June, 1994.

[2] T. M. Wallett and A. H. Qureshi, "Characteristics of a cylindrical disk-loaded slow-wave structure found by theoretical, experimental, and computational techniques," International Journal of Microwave and Millimeter-Wave Computer-Aided Engineering, vol. 4, no. 2, pp. 125-129, 1994.

[3] T. M. Wallett and A H Qureshi, "Theoretical, experimental, and computational evaluation of a tunnel ladder slow-wave structure," NASA Technical Memorandum 106642, June 1994.

[4] K. J. Bunch and R. W. Grow, "The helically wrapped circular waveguide," IEEE Trans. On Elec. Dev., vol. ED-34, no. 8, August 1987.

[5] C. L Kory, "Three-dimensional simulation of helix traveling-wave tube cold-test characteristics using MAFIA," IEEE Trans. On Elec. Dev., vol. 43, no. 8, pp. 1315-1319, August 1996.

[6] Personal correspondence with Gary Groshart of Northrop Grumman Corp., Electronics Systems Division, Rolling Meadows, IL, USA. 



\begin{tabular}{|c|c|c|c|}
\hline \multicolumn{3}{|c|}{ REPORT DOCUMENTATION PAGE } & $\begin{array}{l}\text { Form Approved } \\
\text { OMB No. 0704-0188 }\end{array}$ \\
\hline \multicolumn{4}{|c|}{ 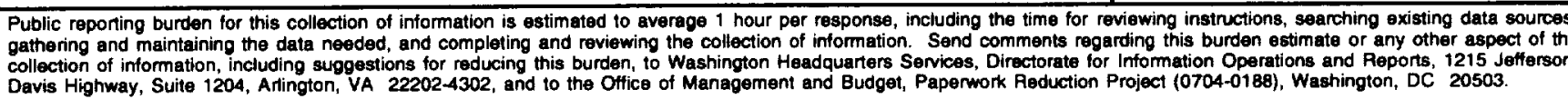 } \\
\hline 1. AGENCY USE ONLY (Leave blank) & $\begin{array}{r}\text { 2. REPORT DATE } \\
\text { May } 1998\end{array}$ & & $\begin{array}{l}\text { ND DATES COVEAED } \\
\text { rechnical Memorandum }\end{array}$ \\
\hline \multicolumn{2}{|c|}{$\begin{array}{l}\text { 4. TTILE AND SUBTTrLE } \\
\text { Technical Characteristics of a Novel Helical-Groove } \\
\text { Traveling-Wave Tube Structure }\end{array}$} & & \multirow{2}{*}{$\begin{array}{l}\text { 5. FUNDING NUMBERS } \\
\text { WU-632-50-5D-00 }\end{array}$} \\
\hline \multicolumn{3}{|c|}{$\begin{array}{l}\text { 6. AUTHOR(S) } \\
\text { Thomas M. Wallett, Karl R. Vaden, Jon Freeman, and A. Haq Qureshi }\end{array}$} & \\
\hline \multicolumn{2}{|c|}{$\begin{array}{l}\text { 7. PERFORMING ORGANIZATION NAME(S) AND ADDRESS(ES) } \\
\text { National Aeronautics and Space Administration } \\
\text { Lewis Research Center } \\
\text { Cleveland, Ohio } 44135-3191\end{array}$} & & $\begin{array}{l}\text { 8. PERFORMING ORGANIZATION } \\
\text { REPORT NUMBER } \\
\text { E- } 10950-1\end{array}$ \\
\hline \multicolumn{2}{|c|}{$\begin{array}{l}\text { 9. SPONSORINGMONITORING AGENCY NAME(S) AND ADDAESS } \\
\text { National Aeronautics and Space Administration } \\
\text { Washington, DC 20546-0001 }\end{array}$} & & $\begin{array}{l}\text { 10. SPONSORINGMONITORING } \\
\text { AGENCY REPORT NUMBER } \\
\text { NASA TM-1998-207414 }\end{array}$ \\
\hline
\end{tabular}

11. SUPPLEMENTARY NOTES

Thomas M. Wallett, Karl R. Vaden, and Jon Freeman, NASA Lewis Research Center; A. Haq Qureshi, Cleveland State University, Cleveland, Ohio 44115. Responsible person, Thomas M. Wallett, organization code 5610, (216) 433-3673.

12a. DISTAIBUTIONAVAILABILITY STATEMENT

12b. DISTAIBUTION CODE

Unclassified - Unlimited

Subject Categories: 33 and 61

Distribution: Nonstandard

This publication is available from the NASA Center for AeroSpace Information, (301) 621-0390.

13. ABSTRACT (Maximum 200 wonds)

Experimental measurements of the dispersion characteristics of a C-band helix structure were carried out and compared to the dispersion characteristics found from a helix model using the three-dimensional electromagnetic computer code MAFIA. A conceptually novel design comprising a helical thread of the same pitch and inner diameter in a cylindrical waveguide also were calculated using the MAFIA code. The helical-groove structure exhibits a smaller bandwidth but at a much higher frequency range than the traditional helical structure for similar physical dimensions. It is physically more robust in construction. The interaction impedance also compares favorably with those of the conventional structure.

\begin{tabular}{|c|c|c|c|}
\hline \multirow{2}{*}{\multicolumn{3}{|c|}{$\begin{array}{l}\text { 14. SUBJECT TERMS } \\
\text { MAFIA; Helix; Interaction impedance; Helical-groove }\end{array}$}} & \multirow{3}{*}{$\begin{array}{l}\text { 15. NUMBER OF PAGES } \\
10 \\
\text { 16. PRICE CODE } \\
\text { A02 } \\
\text { 20. LIMITATION OF ABSTRACT }\end{array}$} \\
\hline & & & \\
\hline $\begin{array}{l}\text { 17. SECURITY CLASSIFICATION } \\
\text { OF REPORT }\end{array}$ & $\begin{array}{l}\text { 18. SECURTYY CLASSIFICATION } \\
\text { OF THIS PAGE }\end{array}$ & $\begin{array}{l}\text { 19. SECURITY CLASSIFICATION } \\
\text { OF ABSTRACT }\end{array}$ & \\
\hline Unclassified & Unclassified & Unclassified & \\
\hline
\end{tabular}

